\title{
Educación para la Paz
}

\section{Un recorrido histórico por la danza y el conflicto en El Salvador:}

\section{La danza en la prevención de la violencia.}

Tania Madrigal-Hueso

Máster en Enseñanza de la Danza

Actriz, bailarina y coreógrafa

Académica-artista de la danza,

Escuela Nacional de Danza Morena Celarié

El Salvador

Recibido: 11 de julio del 2019

Aceptado: 20 de diciembre de 2019

DOI: https://doi.org/10.15359/tdna.36-67.7

\section{Resumen}

En el presente ensayo propongo cómo el movimiento escénico puede ser una herramienta para la prevención de la violencia, a la vez que realizo un recorrido por la danza durante el conflicto armado en El Salvador. Propongo que aquel panorama ensombrecido por el conflicto emergieron los artistas de la danza contemporánea salvadoreña y que, ante el horror, el arte es una herramienta de memoria que sirve también para sanar tejidos sociales tan maltratados por épocas de guerra y violencia generalizada.

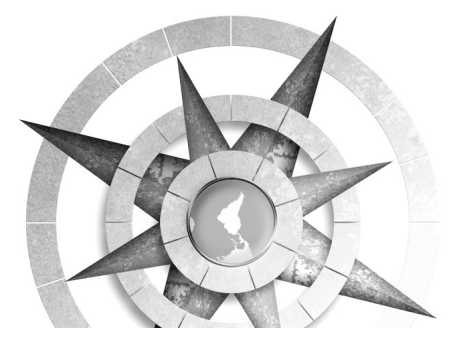

Palabras claves: arte, danza, prevención de la violencia, El Salvador, arte en América Latina
Abstract
In this essay I suggest the way in which the scenic movement can be a tool for the prevention of violence, while at the same time I take a look at dance during the armed conflict in El Salvador. I argue that out of that conflict emerged the Salvadoran con- temporary dance artists and that, in the face of horror, art is a tool of me- mory that also serves to heal the social tissues so maltreated by times of war and generalized violence.

Keywords: Arts, dance, violence prevention, El Salvador, art in Latin America 


\section{Resumo}

Neste ensaio, proponho como o movimento cênico pode ser uma ferramenta para a prevenção da violência, enquanto dou uma olhada na dança durante o conflito armado em El Salvador. Proponho que esse panorama, obscurecido pelo conflito, emergiu como resultado dos artistas da dança contemporânea salvadorenha e que, diante do horror, a arte é um instrumento de memória que também serve para curar tecidos sociais tão abusados pelos tempos de guerra e violência generalizada.

Palavras chave: arte, dança, prevenção da violência, El Salvador, arte na América Latina

El arte de la danza, por antonomasia, es el arte del movimiento humano. Su historia nos muestra su evolución a través del tiempo, desde la necesidad de comunicarse corporalmente, con movimientos que expresan sentimientos y estados de ánimo, como para ritualizar acontecimientos importantes o de diversa índole, hasta convertirse muchos años después, en un elemento de gran valor educativo, porque desarrolla a la vez aspectos corporales, cognitivos y emotivos, y no podemos dejar a un lado su profundo componente social, que es fundamental tanto para su práctica como para su disfrute.
Danza como actividad humana, creada por el ser humano y al servicio de este, como una expresión de símbolos de su propia cultura y sociedad, presenta ciertas características que la conforman, por mencionar algunas:

- Es un arte universal: se hace en cualquier parte del mundo.

- Es una actividad motora: implica movimiento del cuerpo humano con sus partes o como un todo.

- Es polimórfica: para todos los individuos en cuanto a formas físicas, razas, tamaños y/o edades.

- Es polivalente: posee varios valores y/o tiene varias aplicaciones: social, educativa, recreativa, formativa, terapéutica, etc. Pero las adaptaciones que sufren dichas características dependerán, en gran medida, de las necesidades de expresión exclusivas de cada cultura donde se introducen. Estas expresiones no cambian mucho con el paso de los años, pero en general conllevan segmentos históricos de la época y del lugar donde se crearon.

- Entre otras

Pero las adaptaciones que sufren dichas características dependerán, en gran medida, de las necesidades de expresión exclusiva de cada cultura donde se introducen. Estas expresiones no cambian mucho con el paso de los años, pero en general conllevan seguimientos

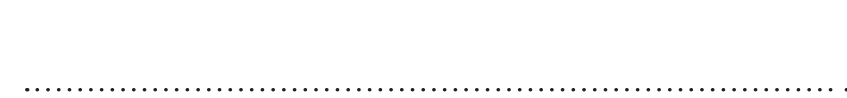
110 Un recorrido histórico por la danza y el conflicto en el salvador: La danza en la prevención de la violencia.
Tania Madrigal-Hueso
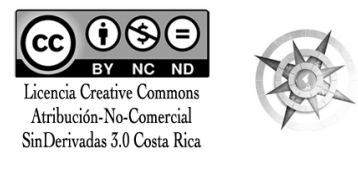
históricos de la época y del lugar donde se crearon.

Ahora bien, El Salvador, país al cual pertenezco, es considerado el país más pequeño del centro de América (20 $742 \mathrm{~km}^{2}$ ) y uno de los países más poblados sobre el planeta, tomando en cuenta su cantidad de habitantes versus. su territorio, con una población para el año 2014 de 6279783 habitantes (290 hab. $/ \mathrm{km}^{2}$ ). Pero haber nacido en un país como El Salvador, tan pequeño y a la vez tan grande en cantidad de personas, cosas, ruido, movimiento, en fin, en historias que suenan a guerra, a hambre, a la lucha, al pasado que continúa siendo el hoy -el presente-y probablemente el mañana... Guerras surgidas quizás por la desigualdad social, por la falta en el cumplimiento de los derechos mínimos del ser, de aquella voz llamada popular, de la inequidad... Guerras que ahora solo nos pasan la factura.

Dentro de tanta convulsión y caos, de denominado simplemente como "conflicto armado", aunque nunca declarado así oficialmente, se desarrolló entre 1980 y 1992 . El país vivió un ambiente de crisis política y social desde la década de 1970. Sin embargo es interesante señalar que de aquí surge una generación de grandes artistas, un movimiento de expresión escénico-corpórea donde el poder moverse, decir con gestos aquello por lo que mataban al que se atre- viera a decirlo con palabras, permitía a muchos ir a las plazas, universidades, y escenarios de todo tipo. A estos escenarios que me gusta llamar "escenarios de la vida" acudían aquellos artistas para decir a otros lo que todos miraban, olían, palpaban, experimentaban: los secretos a voces y a gritos.

Fue una revolución de gente comprometida, de gente distinta, de artistas a los cuales les costaría muy caro su práctica artística, pues pagaron con exilio, secuestro, tortura, silencio y violaciones de todo tipo, simplemente por el hecho de expresarse mediante su arte "y decir las verdades".

Como dato histórico importante de conocer, para 1951 (antes de la guerra) se crea la primera Escuela Nacional de Danza (END) (Posteriormente llamada, Morena Celarié, que es la escuela con más trayectoria en la formación en Danza en el país, con sesenta y cuatro años de existencia, como una institución gubernamental creada en sus inicios con bases en la formación de bailarines en Ballet Clásico, con una línea más de entretenimiento y entrenamiento.

El auge, establecimiento y desarrollo del ballet en El Salvador abarca más o menos dos décadas; hasta que a principios de la década de los años setenta es introducida la danza moderna (durante la guerra) con base en la técnica Limón aplicada por los 
esposos norteamericanos Nightingale, quienes venían como parte de los cuerpos de paz, con la misión de apoyar a estas poblaciones tan dañadas por el conflicto. Se dice que esta pareja logró aprovechar los talentos danzarios de la época para crear grandes obras de danza moderna y formar bailarines que se dedicarían no solo a la danza por la danza, sino a utilizar esta danza para denunciar todo aquello que el pueblo salvadoreño vivía.

Alrededor de 1986-1987 el Departamento de Danza Moderna optó por cambiar su nombre por el de Danza Contemporánea, ya que parecía lo ideal o porque les permitía abarcar tanto el concepto de lo tradicional como el de vanguardia, lo cual se traducía en proyectar la realidad y el contexto de El Salvador de entonces.

Surgieron por esos años varios grupos de danza contemporánea basándose en ese concepto, el cual explotaron creativamente y muy acertadamente como medio para expresar tanto la crisis de la época como el medio vertiginoso que padecía El Salvador. Fue en esta época que la danza contemporánea logró su mayor auge en el desarrollo y reconocimiento como parte del arte danzario de El Salvador.

Según un artículo La Prensa Gráfica con título: "Dos décadas de movimiento" y "La guerra inspiró a corógrafos y bailarines de danza contemporánea a hacer de su arte una denuncia" (Guevar, 18/01/2004, s/p). Dicho artículo señalaba textualmente qué significaba danzar bajo la lluvia, a pleno sol, a suelo raso y hasta con los guardias nacionales en posición desafiante atrás del público.

En este panorama ensombrecido por el conflicto, emergían los artistas de la danza contemporánea salvadoreña. Era el fruto de la creación del Departamento de Danza Moderna, iniciado en la primera mitad de la década de 1970 en la Escuela Nacional de Danza Morena Celarié (END).

Sin embargo, los jóvenes que irrumpían en el convulso escenario nacional habían arrancado con la misma fuerza de la guerra. Con firme decisión, dejaron los escenarios con todas las condiciones técnicas para ir a bailar a donde estaba el público.

Así recuerda el coreógrafo y bailarín Francisco Castillo, quien, junto a un quinteto de jóvenes entrenados en la END, creó el grupo Evolución. Un colectivo que evolucionó y desapareció a la par de la guerra.

Ellos bailaban justo en el límite de "lo aceptado y lo prohibido" por las partes involucradas en el conflicto, recuerda Castillo. Pero la situación

112 Un recorrido histórico por la danza y el conflicto en el salvador: La danza en la prevención de la violencia. 
había contagiado en gran medida sus propuestas. La toma de conciencia sobre la realidad nacional era inevitable y un elemento casi obligatorio en sus trabajos.

La mayoría de montajes de entonces, recuerda Castillo, eran coreografías de canciones etiquetadas como "de protesta” interpretadas por Mercedes Sosa, Silvio Rodríguez y otros cantantes que florecieron en esta época como exponentes del folclor latinoamericano.

Tanto la danza clásica como la contemporánea no decayeron con el conflicto, "más bien cobró fuerza porque los que nos quedamos vimos que era lo único que podíamos hacer" afirma Sonia Franco, quien fue directora de la END en el 2004... Ella recuerda que el grupo Evolución se igualaba a las compañías independientes de México y del resto de Centroamérica.

Las disputas por las apreciaciones de la danza y los compromisos sociales que los acorralaban fracturaron Evolución en los noventa, recuerda Castillo. Sin embargo, los disidentes encontraron refugio en la Universidad Nacional de El Salvador (UES), donde se les abrieron espacios para ensayar y manifestar su arte. Ahí fueron acogidos, además de Castillo, Yasmín Hernández y Alfredo Pérez, entre otros, quienes bautizaron su grupo como 21-91.
Con el fin de la guerra se liberaron del peso del conflicto y la danza contemporánea tomó otro camino.

Para finales del siglo XX (postguerra), el ballet clásico, la danza contemporánea y la danza folklórica gozaban de una muy buena reputación en el medio salvadoreño; gracias también al notorio impulso y apoyo de instituciones nacionales e internacionales como el Ballet Folklórico del Instituto Salvadoreño de Turismo (ISTU), y algunos de los grupos de danza independiente, tales como Evolución, Barranco y otros de la época.

El siglo XXI aporta la práctica de nuevos géneros danzarios al país, como lo son: el hip-hop, danzas consideradas regionales, como el belly dance o danza del vientre, las danzas de tipo hebreo, los bailes de salón como el tango, la samba, la cumbia, danza urbana, entre otros, proyectados por los grupos de danza de variedades o populares e incluso por grupos estudiantiles. Sin duda, con una línea más de entretenimiento y recreación que de formación y/o prevención.

En la actualidad, la danza y las artes en general, pese al abandono inminente que por años hemos tenido por parte de nuestros Gobiernos en turno, hoy en día nos hemos convertido en una estrategia política poderosa para la solución de todos los males acaecidos por la postguerra, con un enfoque sociocultural 
de sensibilización y prevención de la violencia, prioritariamente.

Pareciera que en los últimos años se han dado cuenta, tanto los organismos gubernamentales como no gubernamentales, de la poderosa herramienta y del impacto que tienen las expresiones artísticas en el ser humano.

Será que este fenómeno proporcionará cambios en los siguientes aspectos:

- Mejoras en las condiciones de los artistas (atención en salud, oferta laboral, pensiones, profesionalización, etc.)

- Insumos necesarios y / o indispensables para desarrollar procesos y proyectos artísticos (fondos para la creación, investigación, producción, capacitación, etc.)

- Espacios convencionales y no convencionales para la proyección artística, formación de público, proyectos-talleres permanentes de sensibilización, etc.

- Una currícula para las escuelas que busque formar a nuestros niños y jóvenes con programas integrales tanto en lo académico como en lo artístico.

- Entre otras

En cuanto a esto último que menciono sobre una currícula para la escuela, deseo señalar un tema más allá de nosotros los artistas (que somos solo una parte de nuestras poblaciones), el énfasis en que los niños, las niñas y los jóvenes necesitan urgentemente proyectos educativo-artísticos diferentes, que los lleven a experimentar algo definido y útil para sus vidas.

Afirmo con ello la palabra urgentemente, porque hasta la fecha las llamadas estrategias de sensibilización y programas para la prevención de la violencia en estas poblaciones tan vulnerables son propuestas muy lejanas del deber ser, y es inminente la necesidad real de convertir el pensamiento de nuestro pueblo con respecto al arte, a los artistas, a la cultura, o simplemente encontrar su propia identidad, con programas serios, permanentes (continuos en el tiempo) y supervisados por personas capacitadas en las diferentes áreas artísticas; además, es fundamental llegar a la comprensión de que el arte y la cultura deben formar parte integral del ser humano, en su formación desde las primeras etapas de aprendizaje, por ende, de vida.

Por tanto, la importancia de implementar programas de enseñanza-aprendizaje de un arte como la danza, que favorezcan el desarrollo personal y la integración con las personas y el entorno en el que viven, que favorezcan la autoconfianza a través del control del cuerpo, que aumenten la capacidad de expresar y desenvolverse en el tiempo

114 Un recorrido histórico por la danza y el conflicto en el salvador: La danza en la prevención de la violencia. 
y el espacio, que les facilite la relación con los demás y el conocimiento de sí mismos, que fomenten la superación de estereotipos y prejuicios por cultura y sexo, que ayuden a vencer la timidez y a desinhibirse, que sea una alternativa de ocio saludable que establezca modelos de identificación social, entre otros, podrían ser los objetivos iniciales de estos programas o la meta.

Ahora las preguntas para reflexionar serían:

1. ¿Existen en nuestros países políticas sociales y culturales que definan nuestro deber ser?

2. ¿Existen en nuestros países programas integrales (multidisciplinario) que velen por el desarrollo y la mejora de la calidad de vida de nuestras poblaciones?

3. ¿Existen en nuestros países programas artístico-culturales-formativos que se apliquen abarquen no solo las grandes áreas metropolitanas, sino también los diferentes pueblos o ciudades, las zonas o poblaciones con alta vulnerabilidad, las áreas rurales, las urbano-marginales, y que sean continuos en el tiempo y supervisados por personas capacitadas que los lleven cada vez más a mejores condiciones y por ende logros?

4. ¿Existen en nuestros países el presupuesto suficiente y equitativo, la infraestructura idónea y óptima, además de la capacitación, actualización e implementación en el tema curricular y/o formación en distintas artes, desde las primeras etapas de vida-aprendizaje hasta niveles superiores de formación?

5. ¿Existen en nuestros países el verdadero interés y la voluntad de priorizar desde los Gobiernos, desde las poblaciones, comunidades e individuos el tema del arte y la cultura?

La respuesta sigue en espera, porque aunque siguen creándose muchas propuestas interesantes, en el fondo siempre quiere hacerse mucho, pero con poco o nada; quiere crearse una nueva Centroamérica, "una cultura de paz", pero construyéndose solo con buenas voluntades, con buenas intenciones de altruistas y artistas que seguimos en el limbo y sin querer atacar el problema de raíz.

Para El Salvador, la falta de políticas culturales que comprometan a todos los sectores a creer e invertir en la educación, en la cultura, en el arte y el efecto positivo que todo esto traerá a mediano y largo plazo en nuestra población, en nuestra gente, y la concientización de la importancia de todo lo antes dicho, en cada individuo, comunidad y población en general, es para nosotros el verdadero reto. 


\section{El reto}

De acuerdo con la Unesco, al referirse al logro de sociedades democráticas:

La verdadera comprensión exige establecer sociedades democráticas, fuera de las cuales no cabe ni tolerancia ni libertad para salir del cierre etnocéntrico. Por eso, la educación del futuro deberá asumir un compromiso sin fisuras por la democracia, porque no cabe una comprensión a escala planetaria entre pueblos y culturas más que en el marco de una democracia abierta. (Unesco, 2005).

Cualquier tipo de desarrollo en la región centroamericana siempre debe considerarse desde la unidad integra de la sociedad civil, como valor fundamental de una sociedad planetaria globalizada; sin embargo, para ello es necesario, construir caminos que permitan la libre expresión de los ciudadanos, la participación y la convivencia comunitarias.

Impulsar el desarrollo social mediante la puesta en marcha de propuestas basadas en la formación, la recreación y el ocio, el estímulo y la sensibilidad ampliarán en los ciudadanos el sentido de pertenencia al espacio vital-local, potencializarán mediante tal desarrollo la capacidad de autogeneración unificada, de autogestión, y contribuirán a su vez con la búsqueda y propuesta de soluciones a los diferentes problemas que aquejan a las comunidades y sus poblaciones, con consecuencias directas sobre el mejoramiento de los diferentes ámbitos de la sociedad, que al final y de modo directo influyen sobre la vida educativa, social, cultural y anímica.

Pero fomentar un desarrollo social participativo que contribuya al progreso sociocultural de las comunidades es tarea de diversos agentes: Gobiernos, instituciones educativas, universidades, organizaciones locales, ayudas externas; pero, principalmente, de los individuos que las conforman.

La participación, además, ha tendido a considerarse como una forma más o menos mecanicista de gestión de programas y equipamientos, y no como un elemento estructural central del programa o del equipamiento en sí mismo. Replantear cuál debe ser el lugar de la participación ciudadana en las políticas públicas para la cultura es un reto importante que debe abordarse teniendo en cuenta la múltiple gama de posibilidades y opciones que la participación supone. En este mismo orden de cosas:

...merece la pena reflexionar sobre la importancia de promover la existencia de una ciudadanía cultural organizada, una voz excesivamente ausente de los debates,

116 Un recorrido histórico por la danza y el conflicto en el salvador: La danza en la prevención de la violencia. 
grandes o pequeños, sobre la cultura y sus políticas que se dan en nuestro entorno. A menudo la tan manida noción de "sociedad civil" hace referencia exclusivamente a las corporaciones profesionales y a los gremios artísticos que se arraciman en torno a la cultura. Casi nunca a la ciudadanía organizada en tanto que es consumidora cultural o practicante voluntaria de actividades artísticas (Miralles, 2006, p.9).

De tal manera que:

las políticas y medidas relativas a la cultura, ya sean éstas locales, nacionales, regionales o internacionales, que están centradas en la cultura como tal, o cuya finalidad es ejercer un efecto directo en las expresiones culturales de las personas, grupos o sociedades, en particular la creación, producción, difusión y distribución de las actividades y los bienes y servicios culturales y el acceso a ellos (Unesco, 2005, p. 5).

En consecuencia, es necesario agregar que la finalidad principal de las políticas culturales es fijar los objetivos, crear las estructuras y obtener los recursos adecuados para crear un medio humano favorable. En este sentido, existe una gran necesidad de trabajar en la creación de alianzas estratégicas enfocadas en la capacitación y el desarrollo de recursos humanos con una inclusión activa, capaces de ayudar a solventar las carencias de nuestras sociedades, asumiendo el reto con eficiencia y entrega.

Entonces, para poder lograr el objetivo común de las comunidades, creemos es necesario apoyarse en la conciencia, la integración de la persona, la apropiación, la expresión, la comunicación individual y colectiva, el desarrollo de habilidades y destrezas, entre otros aspectos intrínsecamente vinculados: estética, creatividad, producción, difusión, generación de conocimiento y de espacios, atención comunitaria, investigación, memoria colectiva, identidad cultural, rescate del patrimonio, apoyo educativo, estímulo, sensibilidad artística, desarrollo social, organización comunal, identificación de necesidades y problemas; entre otras razones que fundamentan y sustentan las diferentes prácticas sociales, culturales y educativas vigentes y los discursos teóricos multidisciplinarios desarrollados alrededor de estas, en sus distintas formas de expresión. 


\section{Referencias bibliográficas}

Guevar, T. (18 de enero, 2004). Dos décadas de movimiento. Periódico: La Prensa Gráfica. El Salvador.
Unesco. (2005). Convención sobre la protección y la promoción de la diversidad de las expresiones culturales. París. Recuperado de httpp:// unesdoc.unesco.org/images/0014/001429/142919s.pdf .

Miralles, E (2006). Más allá de la gestión cultural: algunas estrategias para una(s) nueva(s) politica(s) pública(s) para la cultura. Recuperado de httpp://www.redinterlocal.org/ spip.php?article634 